\title{
Self-assembled monoterpenoid phenol as vapor phase atmospheric corrosion inhibitor of carbon steel
}

\author{
V. Vorobyova, ${ }^{1}$ O. Chygyrynets ${ }^{\prime 1}$, M. Skiba, $^{2}$ I. Kurmakova $^{3}$ \\ and $\mathrm{O}$. Bondar ${ }^{3}$ \\ ${ }^{1}$ National Technical University of Ukraine "Igor Sikorsky Kyiv Polytechnic Institute", \\ Kyiv, Ukraine. Ave Peremogy 37, Kiev, 03056 Ukraine \\ ${ }^{2}$ Ukrainian State Chemical-Engineering University, Gagarin Ave. 8, Dnipro, \\ 49005 Ukraine \\ ${ }^{3}$ Chernihiv National T.G. Shevchenko Pedagogical University, 53 Hetmana Polubotka str., \\ 14013 Chernihiv, Ukraine \\ *E-mail: corrosionlife@gmail.com
}

\begin{abstract}
The inhibition efficiency of carvacrol as a non toxic volatile corrosion inhibitor for the temporary protection of mild steel was investigated. Weight loss measurements were used to measure the corrosion rate in the absence and presence of these volatile inhibitor compounds. It is demonstrated that the corrosion rate of steel decreases as its concentration increases, and the process of formation of films from the vapor phase has a long-term character. Atomic force microscopy (SEM) revealed that a protective film was formed on the surface of the inhibited sample. Fourier transform infrared (FT-IR) spectroscopy was used to characterize the adsorption of carvacrol on the steel surface. The results suggest the formation of an adsorbed inhibitor film on the steel surface, leading to a decrease in corrosion rate. Persistency experiments were also performed to evaluate the residence time for inhibitors adsorbed on carbon steel. Among the inhibitors tested, inhibitor showed very good corrosion inhibition properties as well as high persistency. The results show that carvacrol, as a mixed inhibitor, had good volatility and short induction period. The adsorption capacity of carvacrol was evaluated using quantum chemical calculations.
\end{abstract}

Key words: atmospheric corrosion, carvacrol, steel, volatile inhibitor, quantum chemical calculations.

Received: November 17, 2017. Published: November 30, 2017

doi: $\underline{10.17675 / 2305-6894-2017-6-4-8}$

\section{Introduction}

Corroded metals cause major losses due to the wide application of metals in various industries. Among the various methods available for protection of metals from corrosion during storage and transportation, the use of volatile corrosion inhibitors occupies a unique place [1-3]. Organic coatings are an effective way to protect metallic substrates from 
corrosion. They are used widely due to low manufacturing costs and ease of application, suitable bulk properties, versatility and aesthetic attributes.

In recent times, researchers have focused their attention on developing greener products due to several social and economic challenges. Due to these concerns, green coatings have been a new trend in corrosion protection and extensive study is necessary to understand the mechanism of the coatings [4-6].

Consequently, some organic molecules extracted from food byproducts appear as an alternative in the field of corrosion inhibition due to their biodegradability and easy availability. Corrosion inhibiting efficiency of natural products on metals has begun to be extensively studied from the end of the nineteenth century in replacement of the extensive use of very efficient inorganic inhibitors or organic molecules [4-6].

In the past two decades many alternative environmentally friendly corrosion inhibitors have been developed. Thus, the research in the field of "green" corrosion inhibitors has been addressed towards the goal of using cheap, effective molecules at low or "zero" environmental impact. In the search of a new strategy natural substances have been considered since most of these substances are safe and can be extracted by simple and cheap procedures [4-6]. Different plant-extracts-based green inhibitors have recently been proposed as nontoxic corrosion inhibitors. Various natural substances have been tested as vapor phase corrosion inhibitors (VCIs). Several work devoted to the study to use natural compounds like wood bark oil [7] thyme, menthol [8,9] as VCIs. With the aim of improving the stability of the organic protective films, treatments other than adsorptive films formation were developed. In continuation of our work, some plant extracts have been studied as effective volatile corrosion inhibitors of steel namely In continuation of our work, some plant extracts have been studied as effective volatile corrosion inhibitors of steel namely Rapeseed cake, Hope Cones, Brushes and skins of grapes and Lavanda, Artemisia extracts [10-15]. Through these studies, it is agreed that the inhibition performance of plant extract is normally ascribed to the presence in their composition of complex organic species such as aldehydes, terpenoids, glycosides, nucleosides, ketones and aldehydes, saturated and unsaturated fatty acids. The inhibition of mild steel corrosion by the studied species of plant raw materials $[10,11]$ is probably attributed to the presence of most important compounds such as a monoterpenoid phenol - Carvacrol.

Carvacrol (2-Methyl-5-(propan-2-yl)phenol) is a natural phenolic derivative component of Hope Cones, Origanum vulgare and Thymus vulgaris essential oils. Through these studies, it is agreed that the inhibition performance of plant extract is normally ascribed to the presence in their composition of complex organic species such as tannins, alkaloids and nitrogen bases, carbohydrates, amino acids and proteins as well as hydrolysis products. These organic compounds contain polar functions with $\mathrm{N}, \mathrm{S}, \mathrm{O}$ atoms as well as conjugated double bonds or aromatic rings, which are the major adsorption centers. Noticeably, the plant extract is a mixture of various components, which results in the complex inhibitive mechanism. It is rather difficult to determine what components present in plant extract create their relatively high ability to inhibit corrosion. A better way is to isolate the components 
and investigate the inhibition of each single component, but it is still difficult to isolate all the components. In addition, it takes long time to isolate the components. Thus, testing the inhibition potential of major components using available pure compounds could be an alternative choice to study the corrosion inhibition of plant extract.

Hence, the objective of this study was to investigate the inhibitory effect of carvacrol as a green volatile corrosion inhibitor mild steel.

Inhibition of carbon steel corrosion by a carvacrol film forming on the metal surface was studied by a volatile inhibiting ability test and electrochemical measurement. Morphology of the film on the carbon steel surface was investigated by SEM, (FT-IR) measurement.

\section{Experimental}

\subsection{Materials and Apparatus}

Mild steel strips were used for the corrosion test and electrochemical measurements. The composition of the mild steel is given in \%: $\mathrm{C} \leq 0.15$; Mn $0.20-0.45 ; \mathrm{P} \leq 0.03 ; \mathrm{S} \leq 0.035$ and $\mathrm{Al} \geq 0.02$. Steel specimens $(50 \times 20 \times 1.5 \mathrm{~mm})$ were used for volatile inhibiting sieve test (VIS). The strips were polished by emery paper of $1 / 0,2 / 0$ and $3 / 0$ rinsed with double distilled water, degreased and dried at room temperature. The inhibitor used was carvacrol with the concentration range from 50 to $600 \mathrm{mg} / \mathrm{L}$. The purity of carvacrol is $99.0 \% \mathrm{w} / \mathrm{w}$ on dried basis. 2-propanol solution of the carvacrol was used as the corrosion inhibitor. Dissolution of carvacrol was directly carried out in solution 2-propanol at room temperature. Figure 1 shows the molecular structure of carvacrol.

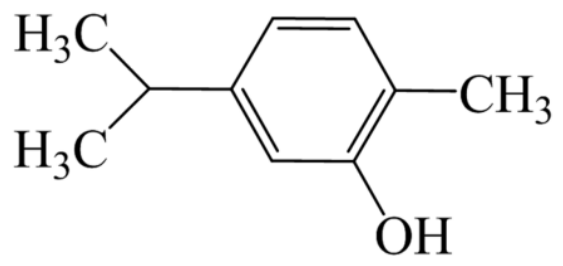

Figure 1. The molecular structure of carvacrol.

\subsection{Gravimetric measurements}

Volatile inhibiting sieve test were applied to evaluate the inhibition effect of the VCI. To obtain reproducible results three samples were used in each test simultaneously. There was a hole in each plate drilled to suspend the sample by a nylon thread. The samples were grinded with $\mathrm{SiC}$ paper to 1000 mesh and were then cleaned in alcohol and rinsed before drying at room temperature. The final geometrical area was $25 \mathrm{~cm}^{2}$. The gravimetric measurement was conducted by suspending the samples in a $250 \mathrm{~cm}^{3}$ conical flask with a tight-fitting rubber cork containing a small dish. The VCI was dispersed in the dish. The samples with freshly prepared surface were mounted on the flask with and without $1.0 \mathrm{~g}$ inhibitor, respectively. After inhibitor film-forming period of 3 days, $15 \mathrm{~cm}^{3}$ deionized 
water was added. The test process included cyclic warming and cooling of the samples in a corrosion testing chamber with varying humidity. One cycle included an $8 \mathrm{~h}$ exposure in a thermostat $\left(50 \pm 1^{\circ} \mathrm{C}\right)$, and $16 \mathrm{~h}$ exposure at room temperature.

Corrosion rates and inhibitor effectiveness are calculated by means of the following equations:

$$
\begin{gathered}
C R=\frac{W_{0}-W_{1}}{S \times T}, \\
I E=\frac{C R_{1}-C R_{2}}{C R_{1}} \times 100,
\end{gathered}
$$

where CRs are expressed in $\mathrm{g} \mathrm{m}^{-2} \mathrm{~h}^{-1} ; S$ is the sample area $\left(\right.$ in $\left.^{2}\right) ; W_{0}$ is initial weight of the sample, and $W_{1}$ is sample weight (in $\mathrm{g}$ ) after the immersion period, $T$ is the immersion period (in $h$ ), and $\mathrm{CR}_{1}$ and $\mathrm{CR}_{2}$ are the corrosion rates without and with inhibitor, respectively.

\subsection{Electrochemical measurements}

To determine the influence of protective surface films on the cathodic and anodic electrode atmospheric corrosion (AC) processes for mild steel, we plotted the potentiodynamic polarization curves for a three-electrode electrochemical cell in air by separating the anolyte from the catholyte (the volume of working solution was $60 \mathrm{~cm}^{3}$ ). We used a cylindrical steel electrode pressed into a Teflon holder and a platinum plate as an auxiliary electrode. The disk end face of the mild steel electrode $0.385 \mathrm{~cm}^{2}$ in area served as the working surface. We plotted the polarization curves in a $0.5 \mathrm{M} \mathrm{Na}_{2} \mathrm{SO}_{4}$ solution used to model the aggressive medium of the $\mathrm{AC}$ of metals. As a specific feature of our electrochemical investigations, we can mention the following fact: the disk-shaped surface of the end face of the working electrode was immersed in surface layers of the working solution by at most $1-2 \mathrm{~mm}$. This enabled us to perform more exact modeling of the AC running on the metal surface in thin layers of condensed moisture. A capillary from the reference electrode was placed near the surface of the working electrode from below. Prior to processing in the VCI vapor, the working electrode was polished and degreased with acetone. The VCI film on the surface was preliminarily formed in vapors of the isopropanol solution of carvacrol and distilled water for $24 \mathrm{~h}$. The polarization investigations were performed by using a PI-50-1.1 potentiostat and a PR-8 programmer. The potential of mild steel was measured relative to the silver-chloride reference electrode. The induced electrode potentials were recalculated relative to the normal hydrogen electrode.

The electrochemical impedance spectroscopy was measured at open circuit potential with a $5 \mathrm{mV}$ AC perturbation at frequency ranging from $100 \mathrm{kHz}$ to $5 \mathrm{mHz}$ with 10 points per decade. The test device and the cell configuration for the EIS measurements were the same as those for the polarization curve tests. To prove reproducibility, the polarization curve tests and the EIS measurements were repeated three times. 


\subsection{Scanning electron microscope (SEM)}

The surface morphology and coating were examined by FEI E-SEM XL 30. For SEM images, a $1 \mathrm{~cm}^{2}$ specimen was taken.

\subsection{Fourier Transformation Infrared Spectroscopic Studies (FT-IR)}

The registration of IR spectra the carvacrol was performed on IR-Fourier spectrometer Jasco FT/IR - 4000. To characterize adsorbed film on the metal, $1 \mathrm{~cm}^{2}$ surface area of mild steel was exposed to both gas mediums for certain hours and used for surface analysis by FT/IR spectrum. The registration of IR reflectance spectrums of the sample surface pretreated by volatile corrosion inhibitors was performed by IR Fourier-transformed spectroscopy (Perkin Elmer) in the range of $4000-630 \mathrm{~cm}^{-1}$.

\subsection{Quantum chemical calculations}

Quantum chemical calculations have been performed by the HyperChem 7 [12] package. The geometry optimization was obtained by application of the restricted Hartree-Fock method (RHF) using MNDO approach with PM3 parameterization.

Corrosion inhibition effectiveness of molecules can be compared with the help of various electronic structure parameters. The most popular parameters among these are the eigenvalues of highest-occupied (HOMO) and lowest-unoccupied (LUMO) molecular orbitals, HOMO-LUMO gap electronegativity and chemical hardness [13-19].

According to Koopman's theorem [15], the frontier orbital energies $E_{\text {НОмо }}$ and $E_{\text {LUMO }}$ are related to the ionization potential, $I$, and the electron affinity $A$ of iron and the inhibitor molecule by the following relations: $A=-E_{\mathrm{LUMO}}, I=-E_{\text {Hомо }}$ [14-25]. Pearson and Parr presented operational and approximate definitions using the finite differences method depending on electron affinity $(A)$ and ionization energy $(I)$ of any chemical species (atom, ion or molecule) for chemical hardness $(\eta)$, and chemical potential $(\chi)[21-25]$ :

$$
\chi=-\mu=\frac{1}{2}(I+A)
$$

The hardness $\eta$ of an electronic system is defined as [26, 27]:

$$
\eta=\frac{1}{2}(I-A)
$$

The global softness (S), is the inverse of global hardness and is given as

$$
S=\frac{1}{2 \eta}
$$

It has been reported that the more stable molecular structure has the largest HOMOLUMO energy gap [29]. Therefore, an electronic system with a larger HOMO-LUMO gap should be less reactive than one having a smaller gap. This relationship is based on the 
Maximum Hardness Principle, which states that there seems to be a rule of nature that molecules arrange themselves so as to be as hard as possible.

This principle is among the most widely accepted electronic principles of chemical reactivity and a formal proof of this principle was given by Parr and Chattaraj [24-29]. If bulk iron metal and the inhibitor molecule are brought together, the flow of electrons will occur from the molecule of lower electronegativity to the iron that has higher electronegativity until the value of the chemical potential becomes equal [28-30]. The global electrophilicity index $(\omega)$ was introduced by Parr et al. [26-29] and is given by:

$$
\omega=\frac{(I+A)^{2}}{8(I+A)}
$$

Nucleophilicity $(\varepsilon)$ is physically inverse of electrophilicity $(1 / \omega)$.

The electron charge transfer, $\Delta N$, from base $\mathrm{B}$ to acid $\mathrm{A}$, and the associated energy change $\Delta E$ are given as [31]:

$$
\begin{aligned}
& \Delta N=\frac{\mu_{\mathrm{B}}-\mu_{\mathrm{A}}}{2\left(\eta_{\mathrm{A}}+\eta_{\mathrm{B}}\right)} \\
& \Delta E=\frac{\left(\mu_{\mathrm{B}}-\mu_{\mathrm{A}}\right)^{2}}{2\left(\eta_{\mathrm{A}}-\eta_{\mathrm{B}}\right)}
\end{aligned}
$$

A, B - indices in formulas $(7,8)$;

A - characteristics of the molecule of the test substance;

$\mathrm{B}$ - characteristics of the elemental lattice of the surface of iron.

Substituting the subscripts A and B by "met" and "mol" to designate a metal surface and a molecule, respectively, and replacing the $\mu$ by $-\chi$ gives:

$$
\begin{gathered}
\Delta N=\frac{\chi_{\mathrm{met}}-\chi_{\mathrm{mol}}}{2\left(\eta_{\mathrm{met}}+\eta_{\mathrm{mol}}\right)}=\frac{\Phi-\chi_{\mathrm{mol}}}{2 \eta_{\mathrm{mol}}} \\
\Delta E=\frac{\left(\chi_{\mathrm{met}}-\chi_{\mathrm{mol}}\right)^{2}}{2\left(\eta_{\mathrm{met}}-\eta_{\mathrm{mol}}\right)}=\frac{\left(\Phi-\chi_{\mathrm{mol}}\right)^{2}}{4 \eta_{\mathrm{mol}}}
\end{gathered}
$$

In the equality (10), the electronegativity of metal surface is replaced by the work function for Fe (110) surface, $\Phi$, which theoretically equals $4.82 \mathrm{eV}$, and the hardness, $\eta_{\text {metal }}$ which equals $0 \mathrm{eV}$ for bulk metals [28-30].

The parameters which were defined above are the most important parameters considered in scientific researches about corrosion inhibition. It should be clear that these parameters provide information about electron donating ability of chemical species and the most notable feature of a corrosion inhibitor is its electron donating ability to metals because electron donor chemical species prevent the oxidation of metals. 


\section{Results and Discussion}

\subsection{Inhibition of carvacrol film on the corrosion of carbon steel}

Visual inspection was carried out following the criterion for the volatile corrosion inhibition test. After the volatile corrosion inhibition test, the specimens treated by carvacrol were bright in almost all areas. The corrosion rate values with different concentrations of carvacrol are shown in Table 1.

Table 1. Calculated corrosion rates and inhibition efficiency for volatile corrosion inhibition test (period of film-forming: $48 \mathrm{~h}$; conditions of periodic condensation of moisture (distilled water) for 21 days).

\begin{tabular}{ccc}
\hline Inhibitor concentration, $\mathbf{~ m g / L}$ & Corrosion rates, ${\mathbf{~} \mathbf{~}^{\mathbf{- 2}} \mathbf{h}^{\mathbf{- 1}}}^{\text {Inhibition efficiency (IE), } \mathbf{~}}$ \\
\hline without inhibitor & 0.1879 & - \\
50 & 0.1335 & 28.95 \\
100 & 0.0862 & 54.12 \\
200 & 0.0596 & 68.29 \\
300 & 0.0347 & 81.52 \\
400 & 0.0110 & 94.11 \\
500 & 0.0041 & 97.76 \\
550 & 0.0028 & 98.49 \\
600 & 0.0009 & 99.87 \\
\hline
\end{tabular}

The degree of protection varies within the range $28.95-99.87 \%$ depending on the concentration. The corrosion rate values decrease as the concentration of the inhibitor increases, i.e. the corrosion inhibition enhances with inhibitor concentration. This behavior is ascribed to the fact that the adsorption amount and the coverage of inhibitor on surface increases with the inhibitor concentration. For further studies, the concentration of carvacrol was $600 \mathrm{mg} / \mathrm{L}$. It should be noted that the treatment of specimens in the vapor phase of individual 2-propanol does not improve the corrosion resistance of the metal.

Table 2 shows the corrosion rate and inhibition effectiveness for the VCI obtained with and without a period of VCI film-forming.

It should be noted that the corrosion rate decreases with increasing the film formation time. The inhibition efficiency (IE) increases in the range $69.55-99.87 \%$. The corrosion rate and inhibition effectiveness for the carvacrol after $48 \mathrm{~h}$ film-forming on the specimens were $19.79 \mathrm{mg} / \mathrm{m}^{-2} \mathrm{~h}^{-1}$ and $99.87 \%$, respectively.

This shows that carvacrol can evaporate and adsorb on the carbon steel surface to protect the steel at atmospheric exposure and 100\% humidity. The VCI is transferred to the metal surface by diffusion through the gas phase and are then either adsorbed directly on the metal, or dissolved in surface moisture films giving rise to strong ionic activity. The 
inhibition efficiency after $48 \mathrm{~h}$ of film-forming was higher than that after $12,24 \mathrm{~h}$ of filmforming. This suggested that the corrosion protectiveness of carvacrol film-forming on the steel surface was enhanced by prolonging the carvacrol treatment.

Table 2. Calculated corrosion rates and inhibition efficiency for volatile corrosion inhibition test (Conditions of periodic condensation of moisture (distilled water) for 21 days, $600 \mathrm{mg} / \mathrm{L}$ ).

\begin{tabular}{ccc}
\hline Film-forming time, hours & Corrosion rates, $\mathbf{g} \mathbf{~ m}^{\mathbf{- 2}} \mathbf{h}^{\mathbf{- 1}}$ & Inhibition efficiency (IE), $\mathbf{~}$ \\
\hline Unpre-filmed & 0.1879 & - \\
\hline 12 & 0.0572 & 69.55 \\
24 & 0.0518 & 72.39 \\
40 & 0.0370 & 80.31 \\
48 & 0.0009 & 99.87 \\
\hline
\end{tabular}

The analysis of the results of accelerated corrosion tests shows that the carvacrol protect steel from corrosion under the conditions of periodic moisture condensation (Table 3). The degree of protection varies within the range of $92-93 \%$ depending on the test conditions. The results indicate that compounds can form a protective film on the metal surface, which protects the metal against further corrosion.

Table 3. Calculated corrosion rates $\left(\mathrm{g} \mathrm{m}^{-2} \mathrm{~h}^{-1}\right)$ and inhibition efficiency (\%) for volatile corrosion inhibition test. (Period of film-forming: $48 \mathrm{~h}$; inhibitor concentration: $600 \mathrm{mg} / \mathrm{L}$ ).

\begin{tabular}{ccc}
\hline \multicolumn{2}{c}{ Test conditions } & Carvacrol \\
\hline $30 \mathrm{mg} / \mathrm{dm}^{3} \mathrm{NaCl}_{2}$ & Corrosion rates & 0.0144 \\
$50 \mathrm{mg} / \mathrm{dm}^{3} \mathrm{Na}_{2} \mathrm{SO}_{4}$ & Inhibition efficiency, \% & 92.30 \\
\hline $100 \mathrm{mg} / \mathrm{dm}^{3} \mathrm{NaCl}_{2}$ & Corrosion rates & 0.0130 \\
$100 \mathrm{mg} / \mathrm{dm}^{3} \mathrm{NaHCO}_{3}$, & Inhibition efficiency, \% & 93.10 \\
$100 \mathrm{mg} / \mathrm{dm}^{3} \mathrm{Na}_{2} \mathrm{SO}_{4}$ &
\end{tabular}

As an important characteristic of the films formed on the metal surfaces in the vapor of the volatile inhibitor, we can mention their ability to preserve protective properties (aftereffect) in the course of time in the absence of VCI in corrosive media. For this reason, we investigated the aftereffect of films formed on the metal surface after preliminary holding of the specimens in the vapor of the 2-propanol solution of carvacrol. It was shown (Table 4) that these films give the required aftereffect under the conditions of periodic condensation of moisture over $1 \mathrm{~N} \mathrm{Na}_{2} \mathrm{SO}_{4}$ aqueous solutions.

The protective chemisorption films formed on the surface serve as a barrier for the penetration of electrolytes into the metal. The presence of the aftereffect shows that the nature of the inhibiting action is not connected with the electrostatic adsorption. It is 
caused by the formation of a chemisorption layer of carvacrol on the metal surface. These results infer that the inhibition of corrosion steel is due to blocking of steel surfaces chemically adsorbed molecules.

Table 4. Aftereffect of the films formed on St3 steel from the vapor phase of the 2-propanol solution of carvacrol (Time of formation $48 \mathrm{~h}$; time of experiment $504 \mathrm{~h}$ ).

\begin{tabular}{|c|c|c|c|c|}
\hline \multicolumn{3}{|c|}{ Testing conditions } & $\begin{array}{l}\text { Corrosion rate, } \\
\mathrm{g} \mathrm{m}^{-2} \mathrm{~h}^{-1}\end{array}$ & $\begin{array}{l}\text { Inhibition } \\
\text { efficiency, \% }\end{array}$ \\
\hline \multirow{4}{*}{$\begin{array}{c}\text { Periodic } \\
\text { moisture } \\
\text { condensation }\end{array}$} & \multirow{2}{*}{$3 \% \mathrm{NaCl}$} & $\begin{array}{c}\text { In the vapor phase of isopropanol } \\
\text { solution of carvacrol }\end{array}$ & 0.0672 & 81.6 \\
\hline & & Without inhibitors & 0.3663 & - \\
\hline & \multirow{2}{*}{$\begin{array}{c}1 \mathrm{~N} \\
\mathrm{Na}_{2} \mathrm{SO}_{4}\end{array}$} & $\begin{array}{c}\text { In the vapor phase of isopropanol } \\
\text { solution of carvacrol }\end{array}$ & 0.0176 & 92.5 \\
\hline & & Without inhibitors & 0.2346 & - \\
\hline
\end{tabular}

\subsection{Electrochemical investigations of the partial electrode processes}

The polarization measurement results for the steel and electrode are given in Figure 2. In this figure, the cathode branches of polarization curves that characterize the relation between the rate of the reaction

$$
\mathrm{O}_{2}+\mathrm{H}_{2} \mathrm{O}+4 \mathrm{e} \rightarrow 4 \mathrm{OH}^{-}
$$

and the electrode potential drift to the area of more negative potentials $(E)$ with the increasing polarization. The anode branches that characterize the relation of the metal ionization rate to the metal potential drift to the domain of more positive values of $E$. The intersection of these branches is attained at metal corrosion potential $E_{\text {cor }}$, when the cathode and the anode process reach the same rate. The relation of $E_{\text {cor }}$ to the time carvacrol filmforming is given in Table 5 .

Table 5. Characteristics of the polarization curves of St3 Steel in $1 \mathrm{~N} \mathrm{Na}_{2} \mathrm{SO}_{4}$ after the formation of protective film from the vapor phase of the 2-propanol solution of carvacrol.

\begin{tabular}{|c|c|c|c|c|c|}
\hline \multirow{2}{*}{ Holding time } & \multirow{2}{*}{$\begin{array}{l}\text { Currentless } \\
\text { potential, V }\end{array}$} & \multicolumn{2}{|c|}{ Tafel coefficients, $\mathrm{V}$} & \multirow{2}{*}{$\begin{array}{c}I_{\mathrm{corr}} \\
\mathrm{A} / \mathrm{cm}^{2} 1^{-5}\end{array}$} & \multirow{2}{*}{ IE $(\%)$} \\
\hline & & $b_{\mathrm{a}}$ & $b_{\mathbf{c}}$ & & \\
\hline 0 & -0.46 & 0.10 & 0.15 & 13.6 & \\
\hline 12 & -0.43 & 0.10 & 0.15 & 3.8 & 72.05 \\
\hline 24 & -0.43 & 0.10 & 0.15 & 2.6 & 80.88 \\
\hline 48 & -0.43 & 0.10 & 0.16 & 1.1 & 91.92 \\
\hline
\end{tabular}




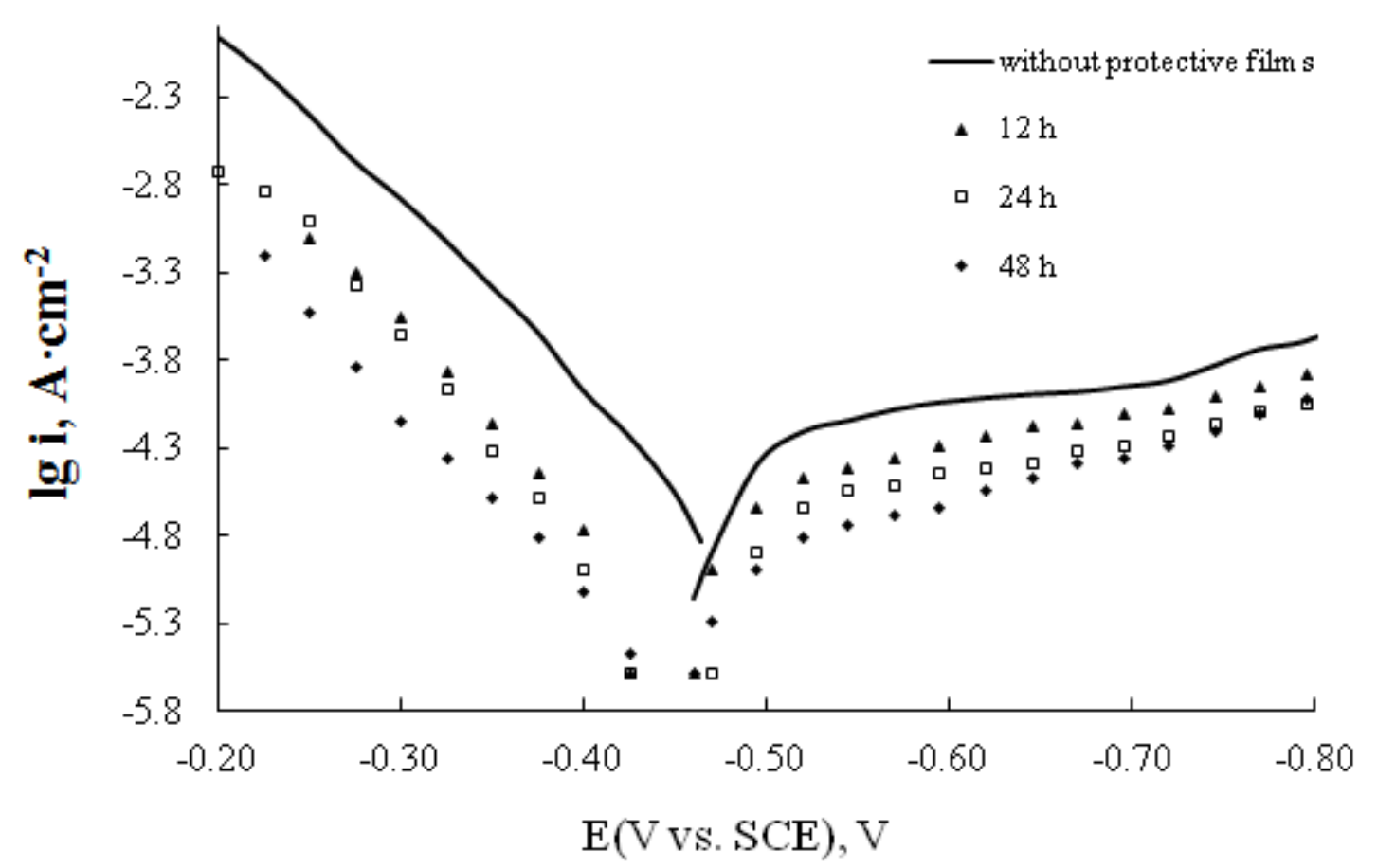

Figure 2. Polarization curves of St3 steel in $0.5 \mathrm{M} \mathrm{Na}_{2} \mathrm{SO}_{4}$ without protective film (curve 1) and with a film formed after holding for 12, 24, or $48 \mathrm{~h}$ in the vapor phase of the 2-propanol solution of carvacrol $(600 \mathrm{mg} / \mathrm{L})$.

In analyzing the influence of VCI films on the rate of the partial electrode processes of anodic oxidation of steel and cathodic reduction of the molecular atmospheric oxygen in a $0.5 \mathrm{M} \mathrm{Na}_{2} \mathrm{SO}_{4}$ solution with and without protective films, it was discovered that, independently of the fact whether the VCI films are present or absent on the steel surface, the rate of cathodic processes is much higher than the rate of anodic processes (Figure 2).

These dependences of the current density on the electrode potentials indicate the presence of fairly complicated multistage processes under the conditions of cathodic and anodic polarization of steel. The anodic curve for the steel electrode in simulated atmospheric corrosion water $\left(0.5 \mathrm{M} \mathrm{Na}_{2} \mathrm{SO}_{4}\right)$ exhibits an active behavior. The cathodic portion of the polarization curve for the blank solution is a composite and represents oxygen reduction.

Both the cathodic slopes and the anodic slopes do not change obviously (Table 5), which indicates that the mechanism of the corrosion reaction does not change and the corrosion reaction is inhibited by a simple adsorption (chemisorption) mode. In the other words, the inhibitor decreases the surface area for corrosion without affecting the mechanism of corrosion and only causes inactivation of a part of the metal surface.

As the time of treatment of the metal by the carvacrol increases to $12 \mathrm{~h}$, the increase in the inhibiting efficiency becomes especially pronounced, which corresponds to the saturation of the surface with the inhibitor and the formation of the strongest bonds between the inhibitor and the metal. It's also seen that all these samples shift the corrosion 
potential significantly to noble direction therefore they are predominantly anodic-cathodic inhibitors.

The inhibition efficiency increases as the pre-treatments immersion time is increased. Both anodic and cathodic reactions are drastically inhibited after $48 \mathrm{~h}$ of exposure of the film-forming. In the presence of volatile compounds extract, the slight change of both $b_{\mathrm{c}}$ and $b_{\mathrm{a}}$ indicates that the corrosion mechanism of steel does not change. These results infer that the inhibitor acts by simple blocking of the available surface area. These components can be arranged as mixed-type inhibitors.

Impedance measurements on the steel electrode in simulated atmospheric corrosion solution were performed open to air at open-circuit potential. Figure 3 represent the Nyquist diagrams for still $1 \mathrm{~N} \mathrm{Na}_{2} \mathrm{SO}_{4}$ without protective film (curve 1) and with a film formed after holding for $48 \mathrm{~h}$ in the vapor phase of carvacrol (curve 2). The equivalent circuit models employed for this system are presented in Figure 4. $R$ is a resistor $\left(R_{\mathrm{s}}-\right.$ solution resistance, and $R_{\mathrm{p}}$ charge transfer resistance), and $C_{\mathrm{dl}}$ represents the double layer capacitance. Since the electrochemical systems show various types of inhomogeneities [31], $C_{\mathrm{dl}}$ can be better substituted by a constant phase element (CPE, Q). The CPE element was introduced formally only for fitting impedance data.

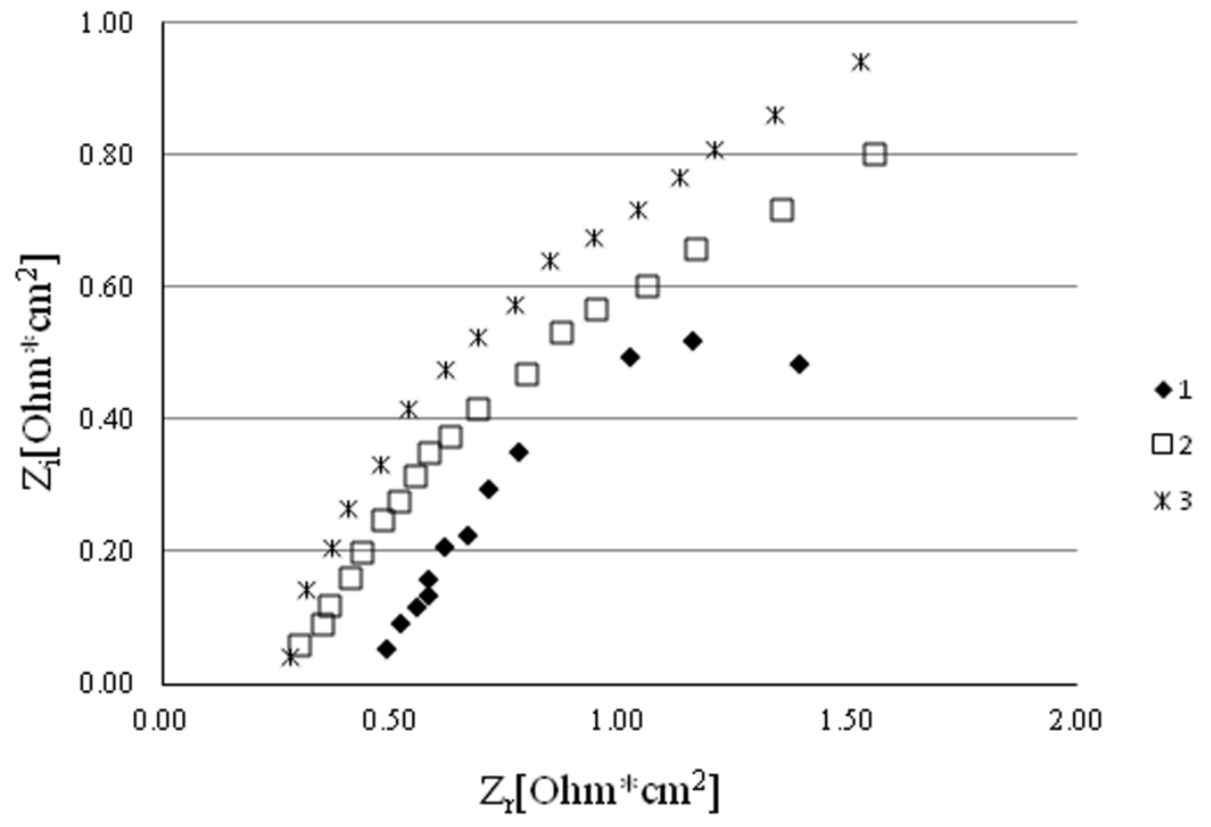

Figure 3. Nyquist plots for the VCI under simulated corrosive atmospheric water $(0.5 \mathrm{M}$ $\mathrm{Na}_{2} \mathrm{SO}_{4}$ ) layer (1, blank; 2, after $24 \mathrm{~h}$ film-forming; and 3, after $48 \mathrm{~h}$ film-forming). 


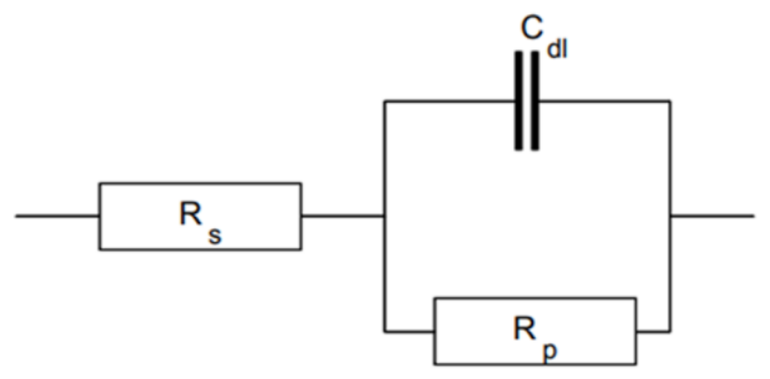

Figure 4. Equivalent circuits for test steel.

Table 6 gives the values of the charge transfer resistance $R_{\mathrm{t}}$ and the double layer capacitance $Q$ obtained from the above plots. It can be seen that the presence of a protective film enhances the values of $R_{\mathrm{s}}$ and reduces the $Q$ values. The decrease in $Q$ may be due to the adsorption of carvacrol in the defects of the metal surface oxide layer. The change in $R_{\mathrm{p}}$ values may be due to the gradual replacement of water molecules by the adsorption of the carvacrol molecules on the metal surface, decreasing the extent of metal dissolution reaction. That's to say, carvacrol has good protection for steel. The capacitance is inversely proportional to the thickness of the interface double layer. This indicates a thicker film formed after $48 \mathrm{~h}$ of carvacrol pre-treatment.

Table 6. Typical parameters obtained from EIS fitting results of St3 steel in $1 \mathrm{~N} \mathrm{Na}_{2} \mathrm{SO}_{4}$ without a protective film and with a film formed after holding for $48 \mathrm{~h}$ in the vapor phase of carvacrol.

\begin{tabular}{cccc}
\hline \multirow{2}{*}{ Sample } & \multicolumn{3}{c}{ parameters obtained from EIS fitting results } \\
\cline { 2 - 4 } & $\boldsymbol{R}_{\mathbf{s}}, \mathbf{O h m ~ \mathbf { ~ m } ^ { \mathbf { 2 } }}$ & $\boldsymbol{R}_{\mathbf{p}}, \mathbf{O h m ~ \mathbf { ~ m } ^ { \mathbf { 2 } }}$ & $\boldsymbol{Q}, \boldsymbol{\mu} \mathbf{F} / \mathbf{c m}^{\mathbf{2}}$ \\
\hline Without protective films & 1.26 & 933 & 0.706 \\
$\begin{array}{c}\text { With protective films (after } \\
\text { 24 h film-forming) }\end{array}$ & 2.24 & 479 & 0.411 \\
$\begin{array}{c}\text { With protective films (after } \\
\text { 48 h film-forming) }\end{array}$ & 3.19 & 510 & 0.489 \\
\hline
\end{tabular}

\subsection{FT-Infrared Reflection Test}

As described above, infrared reflection absorption spectra of the steel specimens were obtained after 24 and $48 \mathrm{~h}$ film-forming periods (Figure 5b,c). The results obtained indicate that after 24 hours we observed several signals that characterize the spectra of phenol and phenolic derivatives. Among these, the contribution at $3288 \mathrm{~cm}^{-1}(v(\mathrm{O}-\mathrm{H})$ vibration band $)$ that is accompanied by $1457 \mathrm{~cm}^{-1}$ (OH in plane deformation vibration), $1277 \mathrm{~cm}^{-1}(\mathrm{C}-\mathrm{OH}$ stretching band) and bands in the 1132 and $976 \mathrm{~cm}^{-1}$ regions $(\mathrm{C}-\mathrm{O}$ stretching vibration) are attributed to the presence of $\mathrm{OH}[32,33]$. Additionally, the peaks at $1649 \mathrm{~cm}^{-1}$ could be assigned to vibration of ketonic structures $(v(C=O))$ that are phenolic derivatives. 


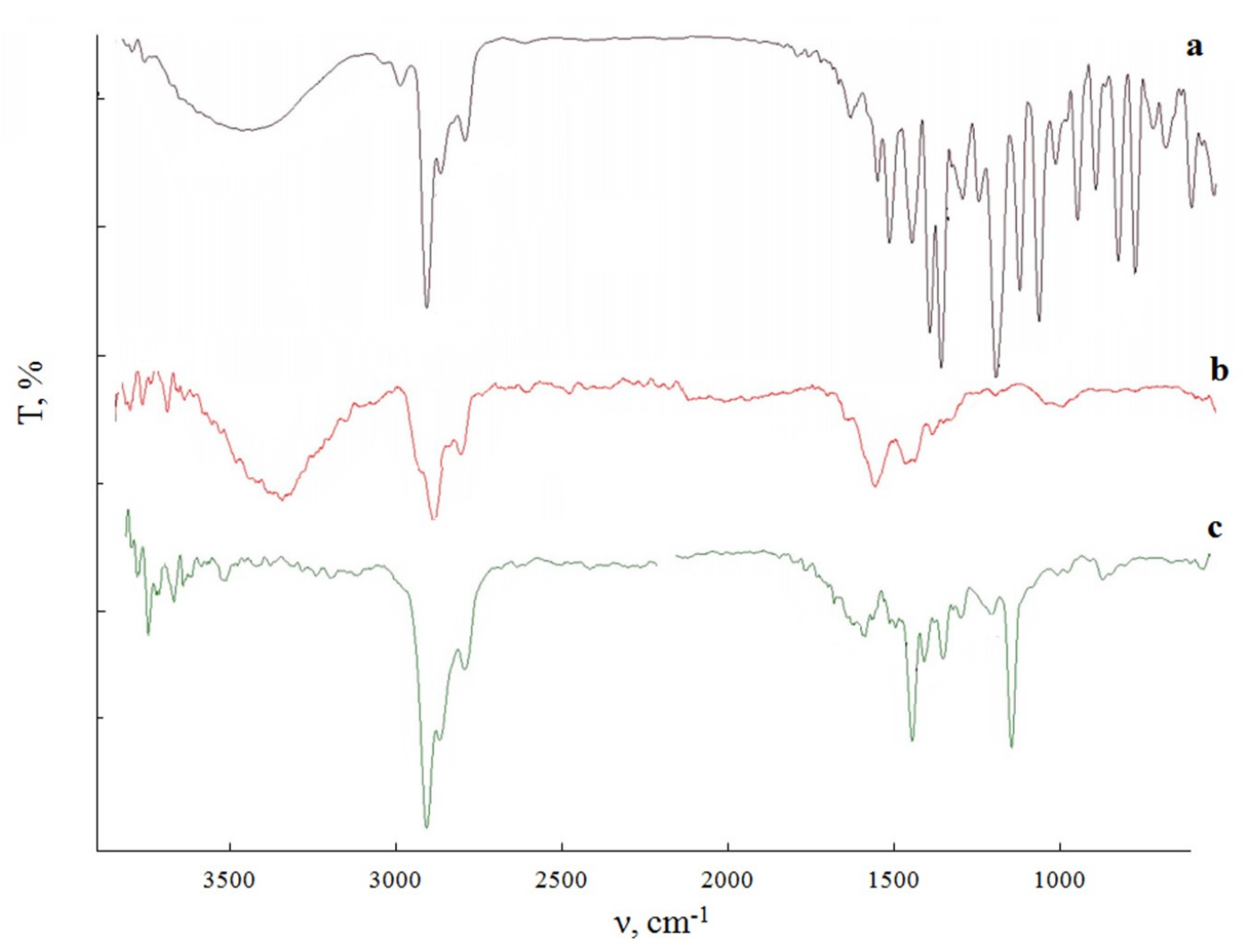

Figure 5. FT-IR spectra of carvacrol (a) and after the formation of a film on mild steel for $12 \mathrm{~h}(\mathrm{~b})$ and $48 \mathrm{~h}(\mathrm{c})$ in the gas-vapor atmosphere in the presence of carvacrol.

Higher transmittance was detected in case of $48 \mathrm{~h}$ film-forming periods. The results show that spectrum with an intense peak at $1181 \mathrm{~cm}^{-1}$ characteristic of polysubstituted phenolic compounds. Peaks at 1494 and $1457 \mathrm{~cm}^{-1}$ are assigned to $\mathrm{C}-\mathrm{C}$ stretching in polysubstituted aromatic rings together with the $3044-2800 \mathrm{~cm}^{-1}$ band.

Besides, the spectrum shows the signal at $1457 \mathrm{~cm}^{-1}$ that corresponds to a $\mathrm{C}-\mathrm{C}$ stretching vibration. Unlike after $24 \mathrm{~h}$ film-forming, peaks at 1243, 1494, 1617 and 1042 $\mathrm{cm}^{-1}$ were detected for steel after $48 \mathrm{~h}$ treatment and can be assigned to ether bonds for phenolic derivatives $[32,33]$. Interestingly, the contribution at $1650 \mathrm{~cm}^{-1}$ is associated to ketone bonds, indicating a probable oxidation of the organic compound to a quinone structure corresponding to two groups of compounds - dimeric and trimeric polymer adducts.

In order to determine the component of the coatings we carried out the analysis of compound by the spectrophotometric method of determination of acetone washouts (with a volume of $20 \mathrm{ml}$ ) obtained from the metal surface preliminarily treated with inhibitors (Figure 6). In the washout from the metal surface held in the atmosphere of inhibitor, we identified almost carvacrol. The peak is shifted, which confirms the formation of dimeric and trimeric compounds of polymer adducts. The presence of the aftereffect indicates that part of molecules in the adsorbed protective layer formed from the vapor phase of 
inhibitors is bound to the metal by chemisorption and is not desorbed in the course of washing of the surface.

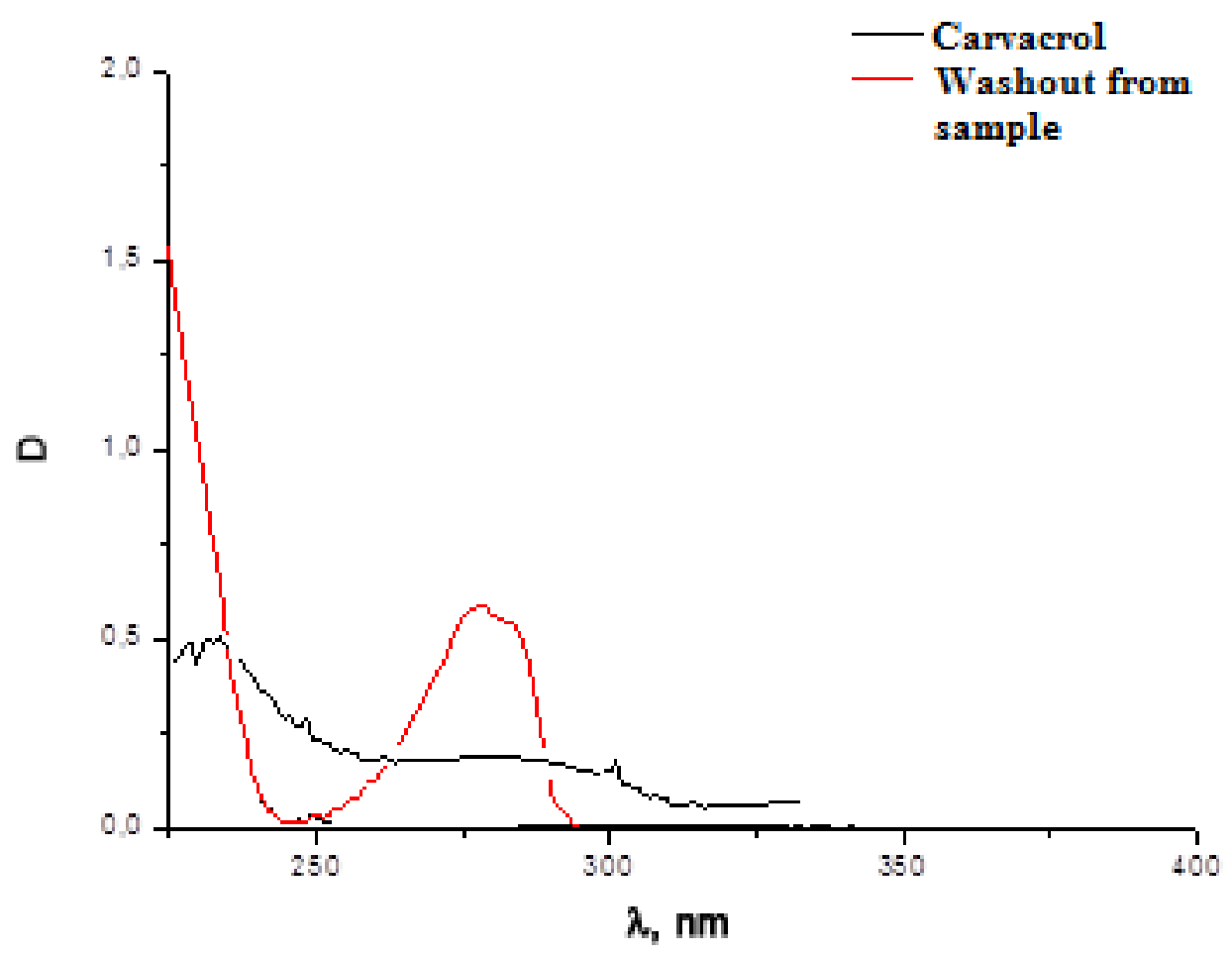

Figure 6. Spectrophotometric determination of acetone washouts (with a volume of $20 \mathrm{ml}$ ) obtained from the metal surface preliminarily treated with carvacrol after $48 \mathrm{~h}$ film-forming.

\subsection{Scanning electron microscope (SEM) surface examination}

SEM images (Figure $7 b, c)$ show the surface morphology of carbon steel surface after the 24 and $48 \mathrm{~h}$ film-forming periods. The surface morphology of the sample before exposure to volatiles of carvacrol there were a few scratches from the mechanical polishing treatment (Figure 7a). It can be noticed that protective film looks very smooth and homogeneous at a high magnification with loosely perceptible cracks due to dehydration process that takes place in the vacuum environment necessary for SEM observations.

This image displays a freshly polished steel surface. It shows a thin and covering surface film. Investigation by Stratmann [34] suggested that adsorption of VCI may form a few protective monolayers. 

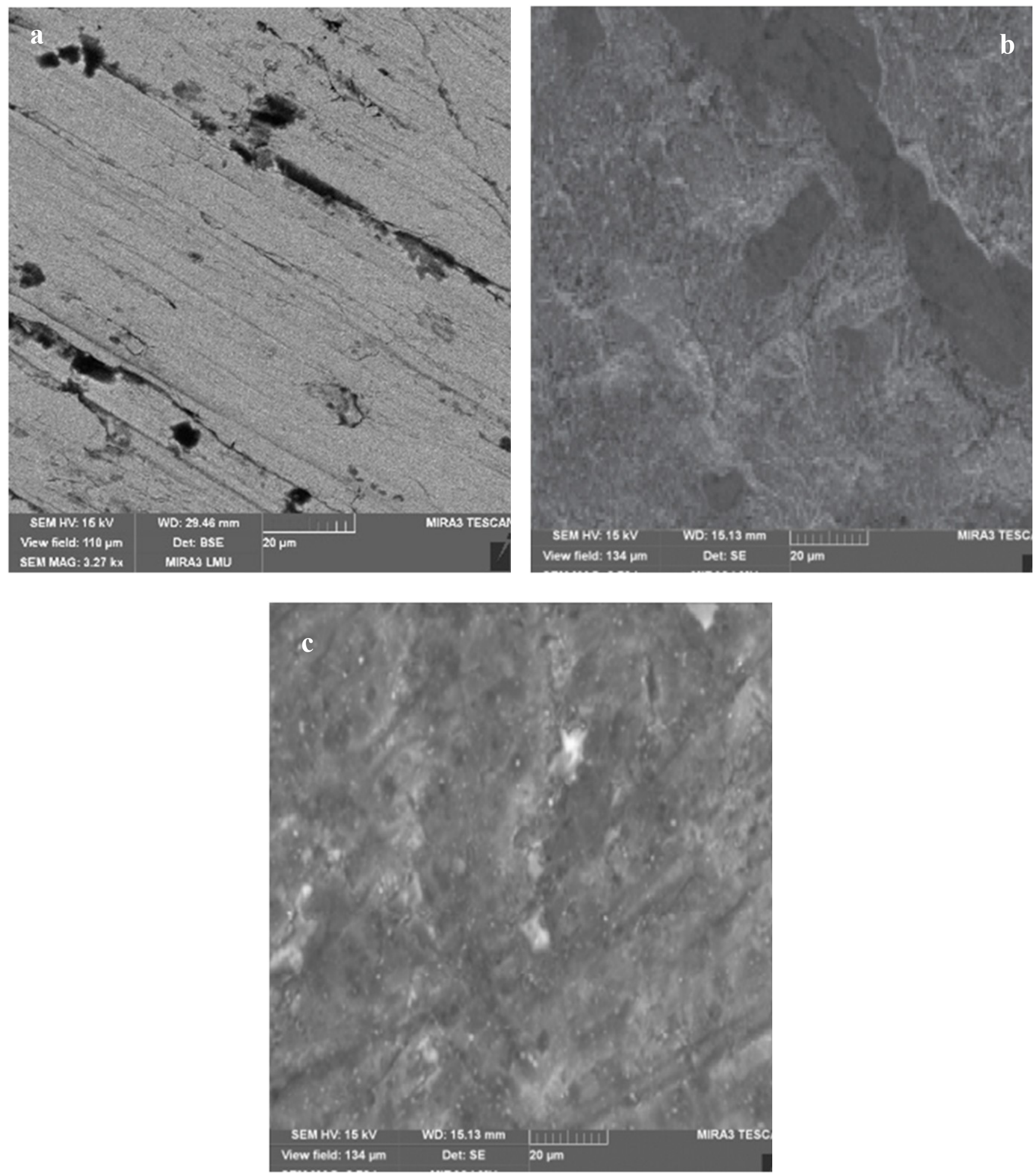

Figure 7. Morphology of the surface of copper specimens: (a) after mechanical treatment, after the formation of a film for 24 (b), 48 (c) $h$ in the gas-vapor atmosphere in the presence of the 2-propanol solution of carvacrol $(600 \mathrm{mg} / \mathrm{L})$. 


\subsection{Quantum chemical studies}

It is generally accpted mechanistic information on corrosion and inhibition processes is very important for proper selection of inhibitors. A systematic approach is needed for characterization of the interaction between the organic inhibitor molecule and the metal or alloy. Such an approach would include elucidation of the interaction by molecular orbital (MO) calculations of the relevant parameters. There are many quantum chemical studies on the inhibition of corrosion with an organic inhibitor.

It should be noted that inhibitor molecules adsorb mainly through electrostatic interactions between the negatively charged atoms and the positively charged metal surface (physisorption) [58]. The higher negative charge was located on benzene ring, therefore adsorption may occurred of atom of oxygen hydroxyl group and benzene ring carvacrol. The optimized structure of Carvacrol is shown alongside the highest occupied molecular orbital (HOMO) and lowest unoccupied molecular orbital (LUMO) electron density surfaces in Figure 8.
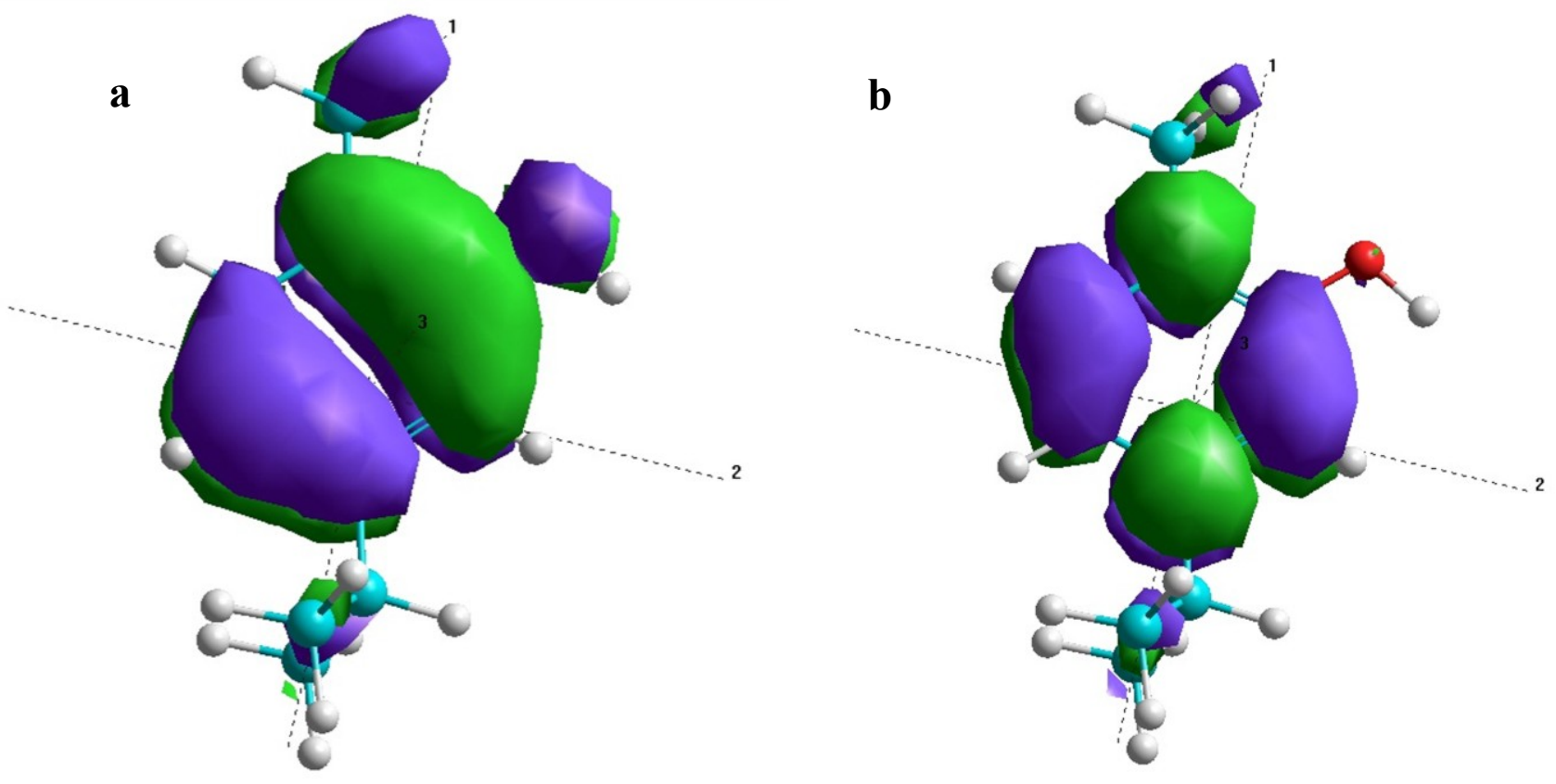

Figure 8. The frontier molecular orbital density distribution of carvacrol: (a) HOMO and (b) LUMO.

The HOMO and LUMO energy values give further insights which are related with the electron donating and accepting ability of a molecule, respectively. The donation forms normal covalent bonds and accepting forms the back donation covalent bonds [13]. The EHOMO was $-9.2695 \mathrm{eV}$ in vapour phase analysis, which indicates a tendency of the molecule to donate electrons to the appropriate acceptor. The HOMO of Carvacrol (Figure 8a) show delocalized electron density contributed from hydroxyl group oxygen atom of carbocyclic ring. The low ELUMO value $(0.23531 \mathrm{eV})$ demonstrated that the 
electron accepting ability of the molecule was higher. The LUMO finds predominant contribution from backbone carbon-hydrogen $\sigma$-bonds.

The separation energy, $\Delta \varepsilon=\left(E_{\mathrm{HOMO}}-E_{\mathrm{LUMO}}\right)$ is parameter which determines the reactivity of a molecule towards a metallic surface and is a very important stability index $[20,13]$. As $\Delta \varepsilon$ decreases, the reactivity of the molecule increases leading to increase adsorption on the metal surface. The energy gap between LUMO and HOMO $(\Delta E)$ was $9.50 \mathrm{eV}$. It reflects the higher inhibition efficiency of carvacrol because the lower $\Delta E$ causes the improvement on the reactivity of the molecule, which facilitates adsorption [13]. Furthermore, the higher dipole moment $(1.2606 \mathrm{D})$ proved that the dipole-dipole interaction of carvacrol and metal surface was higher.

Table 7. Calculated quantum chemical properties for the carvacrol.

\begin{tabular}{ccccc}
\hline Molecule & $\mathbf{E}_{\text {номо }}(\mathbf{e V})$ & $\mathbf{E}_{\text {LUмо }}(\mathbf{e V})$ & $\Delta E_{\mathrm{H}-\mathrm{L}}(\mathbf{e V})$ & Dipole moment $(\boldsymbol{\mu})$ \\
\hline Carvacrol & -9.2695 & 0.2353 & 9.50 & 1.2606 \\
\hline
\end{tabular}

To obtain a clear picture of the interaction between the molecules studied and mild steel surface, intermolecular parameters such as a charge transfer descriptors and the associated energy change should be taken into account [25-34]. Corrosion inhibition of mild steel by organic inhibitors is a complex process and is mainly influenced by charge transport. Electrophilicity is an index which measures the propensity of chemical specie to accept electrons. The higher the value of $\omega$, the higher the capacity of the molecule to accept electrons. Thus, a good nucleophile is characterized by low values of $\mu$ and $\omega$; whereas a good electrophile is characterized by high values of $\mu$ and $\omega$. It is clear in Table 8 that the molecules have low electrophilicity index values and are good nucleophiles. Electrophilicity may be stated as the measure of reactivity to-wards attracting electrons from a nucleophile of a chemical species. Nucleophilicity $(\varepsilon)$ is physically inverse of electrophilicity $(1 / \omega)$. For this reason, it should be stated that a molecule that have large electrophilicity value is ineffective against corrosion while a molecule that have large nucleophilicity value is a good corrosion inhibitor.

A good corrosion inhibitor acts as a strong Lewis base and electronegativity value of inhibitors is an important parameter in terms of electron transfer that comes true between metal and inhibitor. The amount of charge transfer, $\Delta N$, between the molecules and the mild steel Fe surface as calculated is given in Table 8 . A positive value of $\Delta N$ indicates that the molecules act as an electron acceptor, while a negative value of $\Delta N$ indicates that the molecules act as electron donors [28].

Table 8. Calculated quantum chemical properties for the carvacrol.

\begin{tabular}{cccccccccc}
\hline Molecule & $\boldsymbol{I}$ & $\boldsymbol{A}$ & $\boldsymbol{\chi},(\mathrm{eV})$ & $\boldsymbol{\eta},(\mathrm{eV})$ & $\mathbf{S}$ & $\boldsymbol{\omega},(\mathrm{eV})$ & $\boldsymbol{\varepsilon}$ & $\Delta \boldsymbol{E}$ & $\boldsymbol{\Delta} \boldsymbol{N}$ \\
\hline Carvacrol & 9.2695 & -0.2353 & 4.5171 & 4.7524 & 0.21 & 1.236 & 0,809 & 0.00025 & 0.24 \\
\hline
\end{tabular}


Thus, the values in Table 8 shown that carvacrol molecules act as electron donors. If $\Delta N<3.6$, the inhibition efficiency enhances with increasing electron-donating ability to the metal surface as in Lukovits's work. Since Carvacrol is more electronegative than the densely packed steel surface, the charge would flow to Carvacrol from steel surface $(\Delta N<$ 0 ), which has been verified by the explicitly calculated charge transfer.

Theoretical results showed that carvacrol was most probably adsorbed on steel surface and it may connect with other carvacrol molecules via hydrogen bonds.

\section{Conclusions}

Carvacrol has been proved to be a good volatile corrosion inhibitor for the steel corrosion.

Under conditions of modeling of the atmospheric corrosion of mild steel, the VCI films from the developed components decrease the rate of cathodic process more intensely than the rate of anodic process. In this case, the rate of corrosion is controlled by the cathodic process of reduction of the molecular oxygen from air. It is shown that the inhibition of the atmospheric corrosion of steels after treatment in the vapor of volatile compounds carvacrol, occurs due to the blocking of the metal surface by chemically adsorbed molecules.

The quantum-chemical calculations were carried out to predict the adsorption activity of the developed components. The calculated results show that all the molecules (constituting different extract major constituents) have high propensity for donating electrons, have low $\Delta \varepsilon$ and $\eta$ (high reactivity), are good nucleophiles which is characterized by low values of $\omega$, and the energy change associated with the charge transfer to the mild steel surface $\Delta \mathrm{E}$, are all favourable (negative). Our result confirms the generally held assumption that there is a synergistic effect between the different organic molecules present in plant extracts towards enhancing the corrosion inhibition of these extracts on metals and alloys in varied aggressive media.

\section{References}

1. D. Zhang, Z. An, Q. Pan, L. Gao and G. Zhou, Appl. Surf. Sci., 2006, 253, 1343.

2. D. Zhang, L. Gao and G. Zhou, Surf. Coat. Technol., 2010, 204, 1646.

3. M. Sudheer, A. Quraishi, E. Ebenso Eno and M. Natesan, Int. J. Electrochem. Sci., 2012, 7, 7463.

4. D.M. Bastidas, E. Cano, E.M. Mora, Anti-Corro. Meth. Mater., 2005, 52, 71.

5. M.F. Montemor, Active Protective Coatings, 2016, 233, 107.

6. P. Rathi, S. Trikha and S. Kumar, World J. Pharm. Pharm. Sci., 2017, 6, 482.

7. N. Poongothai, P. Rajendran, M. Natesan and N. Palaniswamy, Indian J. Chem. Technol., 2005, 12, 641.

8. P. Premkumar, K. Kannan and M. Natesan, Asian J. Chem., 2008, 20, 445.

9. P. Premkumar, K. Kannan and M. Natesan, J. Metall. Mater. Sci., 2008, 50, 227.

10. V.I. Vorob'iova, O.E. Chyhyrynets' and O.I. Vasyl'kevych, Mater. Sci., 2015, 50, 726. 11. E. Chygyrynets' and V. Vorobyova, Chem. Chem. Technol., 2014, 8, 235. 
12. Materials Studio, Revision 6.0, San Diego, USA, Accelrys Inc., 2011.

13. G. Gece, "The use of quantum chemical methods in corrosion inhibitor studies," Corros. Sci., 2008, 50, 2981.

14. M.H. Jamroz, Vibrational Energy Distribution Analysis VEDA 4, Warsaw, 2004.

15. T. Koopmans, Physica, 1934, 1, 104.

16. S.K. Burak and T.C. Kaya, J. Taiwan Inst. Chem. Eng., 2016, 58, 528.

17. R.G. Pearson, J. Am. Chem. Soc.,1963, 85, 3533.

18. N. Kovacevic and A. Kokalj, Corros. Sci., 2011, 53, 909.

19. R.G. Parr and W. Yang, Oxford University Press, Oxford, UK, 1989.

20. R.M. Dreizler, Density functional theory, Springer, Berlin, 1990.

21. R.G. Parr, R.A. Donnelly, M. Lewy and W.E. Palke, J. Chem. Phys., 1978, 68, 3801.

22. R.T. Sanderson, Chemical bonds and bond energy, Academic Press, New York, USA, 1976.

23. R.G. Parr and R.G. Pearson, J. Am. Chem. Soc., 1983, 105, 7512.

24. P.W. Ayers and R.G. Parr, J. Chem. Phys., 2008, 128, 184108.

25. R.G. Pearson, J. Chem. Edu., 1987, 64, 561.

26. R.G. Pearson, Inorg. Chem., 1988, 27, 734.

27. R.G. Pearson, Proc. Natl. Acad. Sci. USA, 1986, 83, 8440.

28. P.K. Chattaraj, U. Sarkar and D.R. Roy, Chem. Rev., 2006, 106, 2065.

29. R.G. Parr, L. Szentpaly and S. Liu, J. Am. Chem. Soc., 1999, 121, 1922.

30. A.T. Maynard, M. Huang, W.G. Rice and D.G. Covell, Proc. Natl. Acad. Sci. USA, 1998, 95, 11578.

31. D.Q. Zhang, L.X. Gao and G.D. Zhou, Appl. Surf. Sci., 2004, 225287.

32. The Sadtler Handbook of Proton NMR Spectra, Ed. W.W. Simons, Sadtler Research Laboratories, Philadelphia, USA, 1978.

33. M. Gattrell and D.W. Kirk, J. Electrochem. Soc., 1992, 139, 2736.

34. A. Leng and M. Stratmann, Corros. Sci., 1993, 34, 1657. 